\title{
Evaluation of Serum Calcium, Phosphorus and Progesterone in Post-Menopausal Women in Khartoum State-Sudan
}

\author{
Rawan Alobied Saad ${ }^{1}$, Salman Taha Ahmed Elmukashfi ${ }^{1, *}$, Amar Mohamed Saeed ${ }^{1}$, \\ Mosab Omer Khalid ${ }^{2}$ \\ ${ }^{1}$ Department of Clinical Chemistry, Medical Laboratory Science Program, Al-Yarmouk College, Khartoum, Sudan \\ ${ }^{2}$ Department of Clinical Chemistry, Faculty of Medical Laboratory Sciences, Shendi University, Shendi, Sudan
}

Email address:

salmantahamls@gmail.com (S. T. A. Elmukashfi)

${ }^{*}$ Corresponding author

\section{To cite this article:}

Rawan Alobied Saad, Salman Taha Ahmed Elmukashfi, Amar Mohamed Saeed, Mosab Omer Khalid. Evaluation of Serum Calcium, Phosphorus and Progesterone in Post-Menopausal Women in Khartoum State-Sudan. International Journal of Chinese Medicine. Vol. 3, No. 2, 2019, pp. 30-33. doi: 10.11648/j.ijcm.20190302.14

Received: May 1, 2019; Accepted: June 3, 2019; Published: July 22, 2019

\begin{abstract}
Objective: This study was conducted to show importance of preventive measures like calcium supplementation or hormonal therapy to prevent fractures. Material and Methods: This is a comparative (analytical study), case control study. This study includes 50 blood samples, a 30 blood samples were collected from Sudanese post menopause women in a period between March to June 2018, chosen randomly from Umdwanban village, and 20 apparently healthy individuals as control to assess the effect of post menopause on calcium, phosphorus and progesterone. Self-administered questionnaire was used to collect the data. Three $\mathrm{ml}$ of venous blood were collected by using sterile disposable syringes and poured into lithium heparin containers, immediately centrifuged and plasma separated transferred in a plain container and processed. Stored at- $20^{\circ} \mathrm{C}$ until analysis. These samples were evaluated for the serum levels of calcium and phosphorus determined by colorimeter and progesterone by Tosoh AIA 360, and the obtained results were analyzed by SPSS. Results: The study results showed that serum level of calcium and phosphorus was significantly changed $(p<0.05)$ in post menopause women, the serum level of calcium is decreased and phosphorus is increased in post menopause women. The mean of serum calcium was 6.733 in test group and 8.955 in control group with p.value of 0.029 and the mean of serum phosphorus was 5.570 in test group and 3.480 in control group with p.value of 0.031 . And show a non-significant difference in the serum level of progesterone between the test group and control group (P-value $=0.447$ ). Also the study showed the age and social status of the post menopause women have no effect on the serum level of calcium, phosphorus and progesterone. Conclusion: This study concluded that the serum level of calcium is decrease and phosphors is increase while progesterone is unaffected. And the age and social status of post menopause have no effect on the serum level of calcium, phosphors and progesterone.
\end{abstract}

Keywords: Post-Menopausal Women, Calcium, Phosphorous, Progesterone, Sudanese

\section{Introduction}

Menopause is the permanent cessation of menstruation. It is characterized by the menstrual changes that reflect oocyte depletion and subsequent reduction in ovarian hormone production. Menopause typically occurs in middle age, during the early 45 or late 50 years, signaling the end of the fertile phase of life. It is considered as premature when it occurs before 40 years of age but is otherwise normal. According to WHO the term menopause is defined as dating from the final menstrual period, regardless whether the menopause was induced or spontaneous [1, 2]. The post menopause lasts about 10-15 years and is followed by senescence from about 65 years of age to the end of life [3]. 
Characteristically it begins with the menstrual cycle irregularity and extends to one year after permanent cessation of menses. Beginning as early as 10-15 years before menopause there is shortening of the follicular phase of the cycle, and so the length of the menstrual cycle starts decreasing [4]. Insufficient follicular development results in inadequate estrogen production with little estrogen available to stimulate the endometrium which results in amenorrhea. Menopause is not related to menarche, race, and socioeconomic status, number of pregnancies, lactation, or taking of oral contraceptives $[5,6]$. It is however directly associated with smoking and genetic disposition. Smoking induces premature menopause [7].

The calcium and phosphate is most important for the normal body function and their regulation depend on the hormonal function. This hormone including the hormone that produced by the ovary like progesterone $[8,9]$.

Psychological symptoms of menopause: Psychological symptoms include anxiety, poor memory, inability to concentrate, depressive mood, irritability, mood swings, less interest in sexual activity [10].

Signs and symptoms menopause: During early menopause transition, the menstrual cycles remain regular but the interval between cycles begins to lengthen. Hormone levels begin to fluctuate. Ovulation may not occur with each cycle [11].

Diagnosis of menopause: One way of assessing the impact on women of some of these menopause effects are the Greene climacteric scale questionnaire, the Cervantes scale and the Menopause rating scale $[12,13]$.

Vagina and uterus: In post-menopausal women, however, any genital bleeding is an alarming symptom that requires an appropriate study to rule out the possibility of malignant diseases. Symptoms that may appear during menopause and continue through postmenopause include: painful intercourse, vaginal dryness and atrophic vaginitis $[14,15]$.

\section{Materials and Methods}

The study design was comparative (analytical study), case control study. The study was conducted in omdwnban village which is located $45 \mathrm{~km}$ southeast of capital Khartoum. This study was done during the period from March 2018 to June 2018. The study population is divided into two group case and control group, the Case group: Sudanese post menopause women for different duration, age and married status. And the Control group: apparently healthy Sudanese non post menopause women. All volunteers will be enrolled after being fully informed by the aim study, more over an informed consent will be taken from every volunteer. This study was included 50 blood samples. 30 of these samples were collected from Sudanese post menopause women and 20 samples were collected from apparently healthy Sudanese non post menopause women as control group. This data is collected through interview using self-administered questionnaire. Three $\mathrm{ml}$ of venous blood were collected by using sterile disposable syringes and poured into lithium heparin containers, immediately centrifuged and plasma separated transferred in a plain container and processed. Stored at $-20^{\circ} \mathrm{C}$ until analysis. These samples were evaluated for the serum levels of calcium and phosphorus determined by colorimeter and progesterone by Tosoh AIA 360, and the obtained results were analyzed by SPSS.

\subsection{Ethical Committee}

Clearance from University of Shendi ethical committee.

\subsection{Sampling Procedure}

Three $\mathrm{ml}$ of venous blood were collected by using sterile disposable syringes and poured into lithium heparin containers, immediately centrifuged and plasma separated transferred in a plain container and processed. Stored at $-20^{\circ} \mathrm{C}$ until analysis.

\subsection{Data Collection}

This data is collected through interview using selfadministered questionnaire.

\subsection{Quality Control}

The precision and accuracy of all methods use in this study will be checked at each batch using commercially prepared control sera.

\subsection{Data Analysis}

Collected data will be computed and analyzed by using the application of SPSS (statistical package for social sciences) version 21.

\section{Results}

Table 1. Mean and Std.deviation of serum calcium among test and control group.

\begin{tabular}{lllll}
\hline Study group & No of sample & Mean & Std. Deviation & P. value \\
\hline Case & 30 & 6.733 & 1.178 & 0.029 \\
Control & 20 & 8.955 & 0.292 & \\
\hline
\end{tabular}

P. value less than 0.05 significant.

Test used is $\mathrm{T}$ test.

Table 2. Mean and Std.deviation of serum phosphorous among test and control group.

\begin{tabular}{lllll}
\hline Study group & No of sample & Mean & Std. Deviation & P. value \\
\hline Case & 30 & 5.570 & 0.735 & \multirow{2}{*}{0.031} \\
Control & 20 & 3.480 & 0.613 & \\
\hline
\end{tabular}

Test used is $\mathrm{T}$ test.

Table 3. Mean and Std.deviation of serum progesterone among test and control group.

\begin{tabular}{lllll}
\hline Study group & No of sample & Mean & Std. Deviation & P. value \\
\hline Case & 30 & 0.641 & 0.350 & \multirow{2}{*}{0.447} \\
Control & 20 & 5.347 & 5.675 & \\
\hline
\end{tabular}

Test used is $\mathrm{T}$ test. 


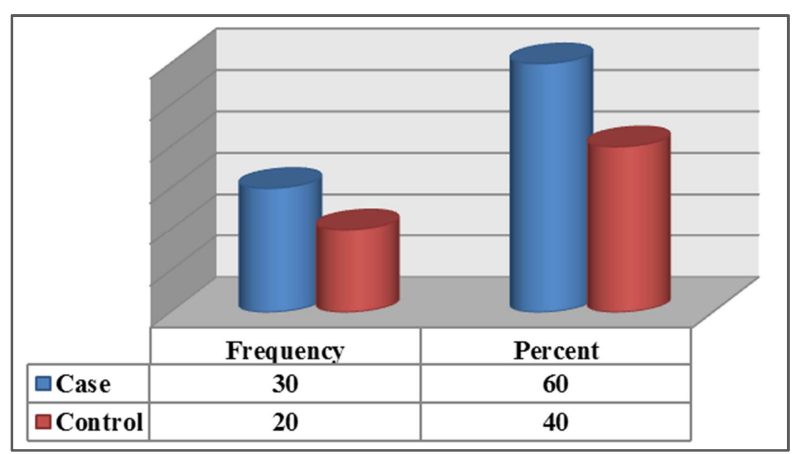

Figure 1. Distribution of study population.

Table 4. Comparison between age among case group for serum calcium, phosphorus and progesterone.

\begin{tabular}{lllll}
\hline & & \multicolumn{2}{l}{ Variable } & \\
\cline { 3 - 5 } Age group & \multirow{2}{*}{ No } & Calcium & Phosphorus & Progesterone \\
\cline { 3 - 5 } & & Mean & Mean & Mean \\
\hline $50-69$ & 15 & 7.026 & 5.346 & 0.7 \\
$70-89$ & 15 & 6.46 & 4.224 & 0.583 \\
P. value & & 0.701 & 0.484 & 0.241 \\
\hline
\end{tabular}

Test used is T test.

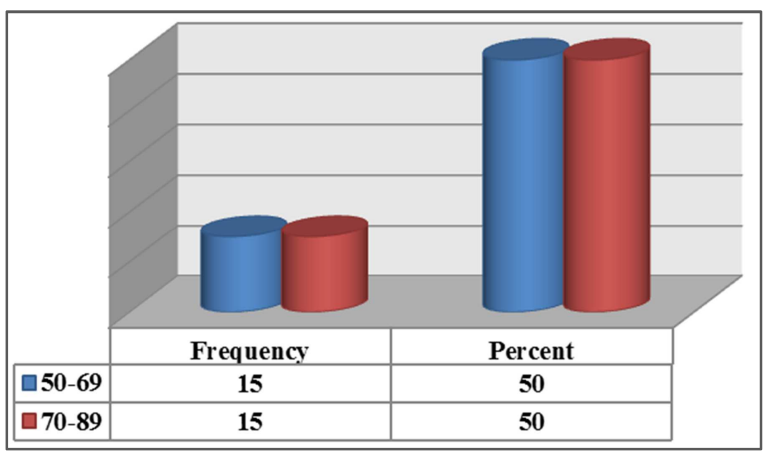

Figure 2. Frequency of age groups among case group.

Table 5. Comparison between social status among case group for serum calcium, phosphorus and progesterone.

\begin{tabular}{lllll}
\hline \multirow{3}{*}{ Social status } & \multirow{2}{*}{ No } & \multicolumn{2}{l}{ Variable } & \\
\cline { 3 - 5 } & & Calcium & Phosphorus & Progesterone \\
\cline { 3 - 5 } & 23 & Mean & Mean & Mean \\
\hline Married & 6.708 & 5.482 & 0.596 \\
Single & 7 & 6.685 & 5.842 & 0.662 \\
P. value & & 0.468 & 0.526 & 0.433 \\
\hline
\end{tabular}

Test used is $\mathrm{T}$ test.

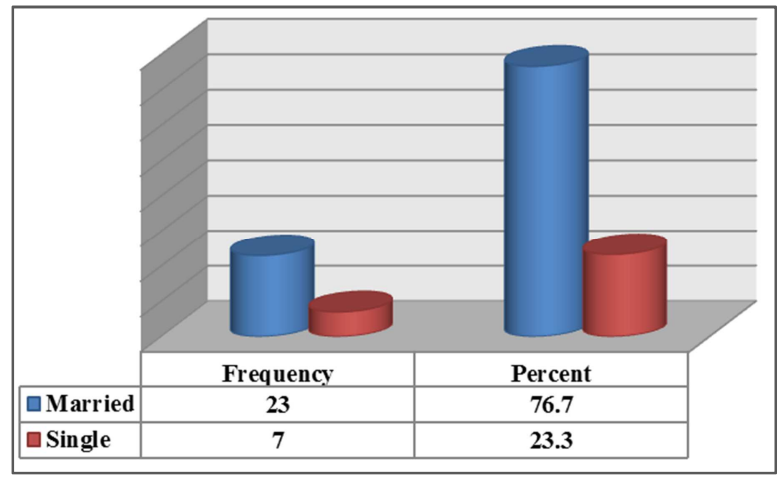

Figure 3. Frequency of social status among case group.

\section{Discussion}

The present study was carried out to investigate serum calcium, phosphors and progesterone among post menopause women, in umdwanban village - Khartoum state in the Sudan during period from March to June 2018; 50 blood samples were collected, a 30 from these samples were collected from post menopause women as case and 20 samples were collected from healthy non post menopause as control group.

In the present study shown statistically significant difference between the mean of the serum levels of calcium and phosphors of the test group compared with that of the control group, the serum level of calcium is decrease in case group than in control group (mean of case $=6.733 \mathrm{mg} / \mathrm{dl}$ and control $=8.955 \mathrm{mg} / \mathrm{dl})$ with $(P$-value $=0.029)$ and the serum level of phosphors is increase in case group than in control group $($ mean of case $=5.570 \mathrm{mg} / \mathrm{dl}$ and control $=3.480 \mathrm{mg} / \mathrm{dl}$ ) with $(\mathrm{P}$-value $=0.031)$, and show a non-significant difference in the serum level of progesterone between the test group and control group $(P$-value $=0.447)$. That illustrated in tables 1,2 and 3. This agree with (Dr. Y.Surya Prabha, Dr. K.Ashalata, et al. 2015) who were reported statically significant different in the serum level of calcium and phosphorus in the study group when compared with control group, the serum level of calcium is decrease in case group than in control group and phosphorus is increase.

Also other similar study cared in Sudan by (Mona Adam AEL malik, Emtithal A, et al. 2016) agree with serum level of calcium, who report significant decreased in serum calcium level in case group compared to the control group and phosphorus level increase in case group compared with control group.

The results of this study showed a non-significant difference between the serum levels of calcium, phosphorus and progesterone of the test group according to the age (Pvalue $=0.701)(\mathrm{P}$-value $=0.484)$ and $(\mathrm{P}$-value $=0.241)$. That illustrated in table 4 and figure 2 .

Also non-significant variation between the serum level of calcium, phosphorus and progesterone according to social status $(\mathrm{P}$-value $=0.468),(\mathrm{P}$-value $=0.526)$ and $(\mathrm{P}$-value $=$ $0.433)$ respectively. That illustrated in table 5.

\section{Conclusion}

This study concluded that the serum level of calcium is decrease and phosphors is increase while progesterone is unaffected. The age and social status of post menopause have no effect on the serum level of calcium, phosphors and progesterone.

\section{References}

[1] Menopause: Overview. PubMedHealth. 29 August 2013. Archived from the original on 10 September 2017. Retrieved 8 March 2015. 
[2] Chuku, Gloria (2005). Igbo women and economic transformation in southeastern Nigeria, 1900-1960. Paragraph 3: Routledge. p. 73. ISBN 0415972108. Archived from the original on 19 May 2016.

[3] Wood, James (2017). "9". Dynamics of Human Reproduction: Biology, Biometry, Demography. Transaction Publishers. p. 401. ISBN 9780202365701. Archived from the original on 10 September 2017.

[4] Hoffman, Barbara (2012). Williams gynecology. New York: McGraw-Hill Medical. pp. 555-56. ISBN 9780071716727.

[5] What causes menopause? Eunice Kennedy Shriver National Institute of Child Health and Human Development. 6 May 2013. Archived from the original on 2 April 2015. Retrieved 8 March 2015.

[6] Takahashi, TA; Johnson, KM (May 2015). "Menopause". The Medical clinics of North America. 99 (3): 521-34. doi: 10.1016/j.mcna.2015.01.006. PMID 25841598.

[7] Warren, volume editors, Claudio N. Soares, Michelle (2009). The menopausal transition: interface between gynecology and psychiatry ([Online-Ausg.] ed.). Basel: Karger. p. 73. ISBN 978-3805591010.

[8] Maxwell D, Fisher E, Estep H (2006). Serum alkaline phosphatase in diabetes mellitus. Journal of the American College of Nutrition, 1986; 5, 55-59.
[9] Shiber JR, Mattu A (2002). Serum phosphate abnormalities in the emergency department. J Emerg Med 2002; 23: 395-400.

[10] What are the symptoms of menopause? Eunice Kennedy Shriver National Institute of Child Health and Human Development. 6 May 2013. Archived from the original on 20 March 2015. Retrieved 8 March 2015.

[11] Healthline. "What causes early menopause". Healthline. Archived from the original on 28 September 2013.

[12] How do health care providers diagnose menopause? Eunice Kennedy Shriver National Institute of Child Health and Human Development. 6 May 2013. Archived from the original on 2 April 2015. Retrieved 8 March 2015.

[13] Fenton AJ (2015). "Premature ovarian insufficiency: Pathogenesis and management". J Midlife Health (Review). 6 (4): 147-53. doi: 10.4103/0976-7800.172292. PMC 4743275. PMID 26903753.

[14] Gougeon A (2016). Dynamics of follicular growth in the human: a model from preliminary results. Hum Reprod 2016; 3: $18-24$.

[15] Greene, JG (2015). "Constructing a standard climacteric scale". Maturitas. 29 (1): 25-31. doi: 10.1016/s0378-5122 (98) 00025-5. PMID 9643514. 